J. Nepal Chem. Soc., Vol. 23, 2008/2009

\title{
Phytochemical Constituents of the Bark of Vitex negundo L.
}

\author{
Ram Chandra Dhakal ${ }^{1}$,Meena Rajbhandari ${ }^{1}$, Surya K. Kalauni ${ }^{1}$, \\ Suresh Awale ${ }^{2}$ and Mohan. B. Gewali ${ }^{1^{*}}$ \\ 1.Central Department of Chemistry, Tribhuvan University, Kathmandu, Nepal. \\ 2.University of Toyama, Institute of Natural Medicine, 2630 Sugitani, Toyama 930-0194, Japan.
}

\begin{abstract}
p-Hydroxybenzoic acid (1) and $\beta$-sitosterol (2) were isolated, and identified from the methanol and hexane extracts of Vitex negundo. The structure of the compounds were established on the basis of spectral analysis.
\end{abstract}

Keywords: p-hydroxybenzoic acid, $\beta$-sitosterol, vitex negundo.

\section{Introduction}

Vitex negundo L. belongs to the family Verbenaceae is a much branched shrub with quadrangular tomentose and densely whitish tomentose branchlets, up to $5 \mathrm{~m}$ tall or sometimes a small, slender tree. The different parts of Vitex negundo are used as medicinal plant by ethnic people for the treatment of various diseases. Its roots and leaves have been used as a tonic and in various ailments. ${ }^{1,2}$ Its leaves are used as aroma, tonic, vermifused for relief headache and catarrh, discutient, useful in dispersing swellings of joints from acute rheumatism and of testes from suppressed gonor. Previous studies on the steam barks of Vitex negundo have resulted in the isolation of many terpenes, sterols, phenolic compounds, flavanoids, alkaloids, organic acids, glucosides, and anthocyanines. ${ }^{3-12}$ Most of them had reported to have antifeedant, antibacterial activities, antiarthritic activity and anti-inflammatory activity. ${ }^{13,14}$ This paper deals with the isolation and identification of the constituents like p-hydroxybenzoic acid (1) and $\beta$-sitosterol (2). The structures of the isolated compounds were established by detailed analysis of their ${ }^{1} \mathrm{H}-\mathrm{NMR},{ }^{13} \mathrm{C}-\mathrm{NMR}$

* Corresponding author. 
spectra. The melting point and Co-TLC results are also used for comparison with the authentic samples.

\section{Experimental Methods}

The melting points were uncorrected. IR spectra were recorded in $\mathrm{KBr}$ disc. ${ }^{1} \mathrm{H}-\mathrm{NMR}$ and ${ }^{13} \mathrm{C}-\mathrm{NMR}$ spectra were recorded in $500 \mathrm{MHz} \mathrm{NMR}$ using $\mathrm{CD}_{3} \mathrm{OD}$ and TMS as a solvent and internal standard, respectively. The purity of the compound was checked on TLC (silica-gel $\mathrm{G}_{254}$ pre-coated) plates.

The steam bark of the $V$. negundo was collected from Bansbari (at $1500 \mathrm{~m}$. altitude), Sindhupalchock district of Nepal.

The air dried and powdered stem bark $(1 \mathrm{Kg})$ of the $V$. negundo (Verbenaceae) were extracted with hexane $(2.7 \mathrm{~L}, 13 \mathrm{~h})$, dichloromethane $(3 \mathrm{~L}, 14$ h) and methanol $(2.5 \mathrm{~L}, 12 \mathrm{~h})$ in a soxhlet extractor to get hexane, dichloromethane and methanol extracts, respectively.

The methanol extract $(15 \mathrm{~g})$ was subjected to column chromatography on silica gel column. The column was eluted initially with hexane and then hexaneethyl acetate and finally with methanol. The sub-fractions were pooled into 21 major fractions on the basis TLC character. The fractions 209-240, 241-270 and 271-303 were obtained by eluting with $1 \%, 2 \%$ and $3 \%$ methanol in ethyl acetate, respectively, showed one major spot with minor impurities on TLC. These fractions were combined and concentrated to get white needle shaped crystals. It was purified by washing with hexane, chloroform followed by re-crystallization with methanol. The obtained $2 \mathrm{~g}$ of the crystal was designated as compound (1).

The hexane extract $(5.0 \mathrm{~g})$ was subjected to column chromatography on silica gel column. The column was eluted initially with hexane and then hexaneethyl acetate and finally with methanol. Fractions of 107 to 134 eluted with 3\% ethyl acetate in hexane were found similar on TLC with a major spot and a minor spot. The concentrated solution was kept for twenty-four hours at room temperature when needle shaped crystals appeared. The crystals were separated from mother liquid and washed successively with pure hexane and 1,2 and 5\% ethyl acetate in hexane. The white substance was re-crystallized from methanol and which showed a single spot on TLC ( $\mathrm{R}_{\mathrm{f} .} 0.52 \mathrm{in} 15 \%$ ethyl acetate in hexane system). The obtained $45 \mathrm{mg}$ of crystals are designated as compound (2).

\section{Results and Discussion}

The compound- 1 was a crystalline solid having melting point at $215^{\circ} \mathrm{C}$; single spot on TLC with $\mathrm{R}_{\mathrm{f}} 0.57$ (50: 50: 0.5, $\left.\mathrm{CH}_{2} \mathrm{Cl}_{2}-\mathrm{EtOAc}-\mathrm{AcOH}\right)$ and 0.67 (95 : $\left.5: 0.5, \mathrm{CHCl}_{3}-\mathrm{MeOH}-\mathrm{AcOH}\right)$. It gave positive test for carboxylic acids with $5 \%$ 
$\mathrm{NaHCO}_{3}$ solution indicating the compound to be carboxylic acid. It gave violet color with ferric chloride solution indicating the presence of phenolic group. The ${ }^{1} \mathrm{H}-\mathrm{NMR}$ spectrum of the compound (1) exhibited two doublet peaks at $\delta 6.81(2 \mathrm{H}, J=8.76)$ and $\delta 7.87(2 \mathrm{H}, J=8.80)$ equivalent to four protons due to the presence of disubstituted benzene ring. The ${ }^{13} \mathrm{C}-\mathrm{NMR}$ spectra of the compound (1) exhibited total five signals including a signal $(\delta 170.1)$ assigned for the carbon of carboxylic acid. The four different signals at $\delta 122.6, \delta 132.9, \delta 116.0$ and $\delta 163.3$ of carbons were assigned for C-1, C-2 and C-6, C-3 and C-5 and C-4 respectively of a benzene ring. On the basis of spectral analysis and by direct comparison with the authentic sample (Co-TLC \& Melting Point), the compound (1) is identified as 4hydroxybenzoic acid ( $p$-hydroxybenzoic acid).

The compound (2) was a crystalline solid having melting point at $136^{\circ} \mathrm{C}$, single spot on TLC with $\mathrm{R}_{\mathrm{f}} 0.47$ (2:8, ethyl acetate/hexane). It gave positive Libermann-Burchard test indicating the compound to be sterol. The mass spectrum showed $\mathrm{M}^{+}$at $\mathrm{m} / \mathrm{z}$ at 414 corresponding to the molecular formula $\left(\mathrm{C}_{29} \mathrm{H}_{50} \mathrm{O}\right)$. The IR Spectrum showed presence of $-\mathrm{OH}$ group $\left(3434 \mathrm{~cm}^{-1}\right)$. The ${ }^{1} \mathrm{H}-\mathrm{NMR}$ spectrum exhibited two singlets at $\delta 1.00$ and 0.67 were assigned for the methyl group of C-19 and C-18, respectively. The doublets at $\delta 0.92(\mathrm{~d}, J=6.1 \mathrm{~Hz}) ; 0.81(\mathrm{~d}, J=6.9 \mathrm{~Hz})$; 0.83 and $(\mathrm{d}, J=6.9 \mathrm{~Hz})$ and $0.84(\mathrm{t}, J=7.3 \mathrm{~Hz})$ were accounted for methyl group at C-21, C-26 and C-27. A signal at $\delta 5.35$ in ${ }^{1} \mathrm{H}-\mathrm{NMR}$ can be accounted for an olefinic proton at C-6. Other multiplet at $\delta 3.52$ equivalents to a singlet proton was assigned for the proton of $\mathrm{C}-3$. The low field signal may be due to the attachment of $\beta-\mathrm{OH}$ group at C-3 carbon. Thus, the assignment of hydroxyl group at C-3 and the double bond at C-5 were assigned accordingly. Three multiplets equivalent to two protons each appeared at $\delta 1.83,2.00$ and 2.27 were assigned for three $\mathrm{CH}_{2}$ groups. The remaining protons were appeared as multiplets at $\delta$ 1.05-1.65. From all the spectral analysis and Co- TLC with authentic sample the compound (2) was identified as $\beta$ sitosterol.

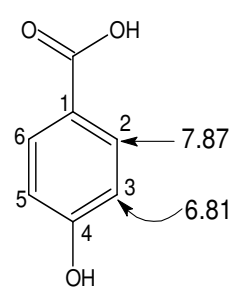

Compound (1)

$\left({ }^{1} H\right.$-NMR of p-hydroxybenzoic acid $)$

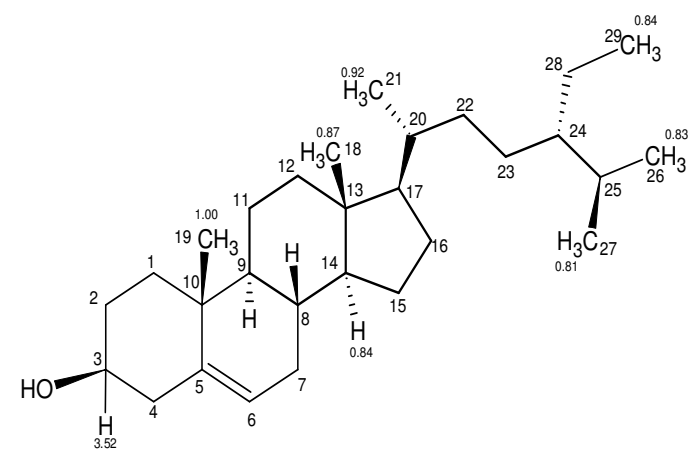

Compound (2)

$\left({ }^{1} H\right.$-NMR of $\beta$-sitosterol) 


\section{Conclusions}

The methanol and hexane extracts of the air dried and powdered steam bark of $V$. negunda resulted in the isolation of $p$-hydroxybenzoic acid (1) and $\beta$-sitosterol (2). The structures of the isolated compounds were established on the basis of their spectral data.

\section{Acknowledgments}

The authors wish to thank Prof. Dr. R. P. Choudhary, Central Department of Botany, Tribhuvan University for the identification of the plant. The research facilities providers; Central Department of Chemistry and Research Centre for Applied Science and Technology, Tribhuvan University, Kirtipur, Nepal are gratefully acknowledged. The research project is partially supported V. Wagen Research Foundation, Hannover, Germany.

\section{References}

1. R. N. Chopra and S. L. Nayar, Glossary of Indian Medicinal Plants, 1956, 256.

2. Wild Edible Plant of Nepal, published by Nepal Government, Department of Plants, Thapathali, Kathmandu, 1982, 1,184.

3. R. Haensel, C. Leuckert and H. Riemer, Phytochemistry, 1967, 4,19.

4. R. Benerji, S. Mohindra and V. G. Malshet, Phytochemistry, 1969, 8,511.

5. I. H. Kawa and Y. Takeo, J. Chem. Soc. Japan, 1940, $61,782$.

6. N. K. Basu and G. S. Singh, Indian J.Pharmacy, 1944, 6,71.

7. V. K. Joshi, J.R. Merchant and V. V. Nadkarny, Indian J. Chem., 1974, 12(2),226.

8. N. K. Bashu and P. P.Lamsal, Quart. J. Pharmacy, 1947, 20,135.

9. T. P. Ghosh and S. Krishna, J. Indian Chem. Soc., 1936, 13,634.

10. G. A. Quazi, S. M. Osman and M. R. Subbaram, J. Oil Tech., 1973, 5,14.

11. G. S. Gupta and D. P. Sharma, Pro. Nat. Aca. Sci., 1973, 43A,268.

12. M. S. Prema and G. S. Misra, Indian J. Chem. 1978, 16B,615.

13. C. Chandramanu and D. Rao, Phytotherapy Research, 2003, 17(2),129.

14. G. N. Chaturvedi and R. H. Singh, Indian J. Med. Res., 1965, 53,71. 